\title{
A New Facile Route to Chlorination of Alcohols via Lewis Acid $\mathrm{AlCl}_{3}$
}

\author{
Hengchang Ma, Zhikang Bao, Lianhua Bai, Wei Cao \\ Key Laboratory of Polymer Materials of Gansu Province, Key Laboratory of Eco-Environment-Related \\ Polymer Materials, Ministry of Education, College of Chemistry and Chemical Engineering, \\ Northwest Normal University, Lanzhou, China \\ Email: mahc@nwnu.edu.cn
}

Received December 30, 2011; revised February 4, 2012; accepted February 21, 2012

\begin{abstract}
Halogenated aluminates $\mathrm{AlCl}_{3}$, applied as efficient chlorination reagent for hydroxyl groups of substitution alcohols is described. Primary and secondary benzylic alcohols could be transformed into corresponding aromatic halides with almost complete conversion and unique selectivity. As chlorination reagent, $\mathrm{AlCl}_{3}$ has an incomparable advantage over others, such as low material cost, commercial availability as well as convenient product isolation.
\end{abstract}

Keywords: Alcohols; Lewis Acid; Nucleophiles; Chlorination

\section{Introduction}

Chlorination of alcohols has been accepted as one of the most important and commonly used transformations in organic synthesis and development of such a procedure is still desirable in academia as well as in industrial research [1-3]. However, due to the lower leaving ability, hydroxyl group is hardly substituted under mild conditions $[3,4]$. The most recent development can be linked to the discovery that the cooperation of $\mathrm{InCl}_{3}$ and $\mathrm{HSiMe}_{2} \mathrm{Cl}$ enable chlorodehydroxylation of alcohols into organic chlorides in the presence of benzyl [5]. The other methods utilize $\mathrm{Ph}_{3} \mathrm{P}-\mathrm{CCl}_{4}$ [6-8], $\mathrm{PCl}_{5}$ [9], thionyl chloride [10], phenylmethyleniminium [10], benzoxazolium [11], Vilsmeier-Haack [12], and Viehe salts [13] as chlorination reagents, among them, $\mathrm{HCl}$ involved chlorination process represents the most prominent example of this reaction class [14-18]. Despite intensive research efforts over the past few years, the conversion usually requires elaborate reagents and quite drastic reaction conditions. Apparently, the undesirable reactions are caused, such as the arrangement or breaking of carbon skeleton, or poor functional group compatibility [7,19-21]. Not only that, for these multicomponent or too reactive reaction systems, some limitations keeps them away from industrial scale production. For instance, difficult product separation, large amount of waste disposal, expensive material cost, and low atom efficiency. In this context, the development of efficient reagents to use in mild conditions and improved preparative procedures allowing efficient conversion of alcohols into alkyl halides have interested organic chemists.
During our recent endeavor with the application of $\mathrm{AlCl}_{3}$ in organic synthesis. We explored that $\mathrm{AlCl}_{3}$ demonstrates excellent catalytic behavior in the oxidation of alcohol and Baeyer-Villiger reaction in the presence of $\mathrm{H}_{2} \mathrm{O}_{2}$ or Oxone ${ }^{\circledR}\left(2 \mathrm{KHSO}_{5} \cdot \mathrm{KHSO}_{4} \cdot \mathrm{K}_{2} \mathrm{SO}_{4}\right)$ [22,23]. In the ongoing research programs, we concerned that reaction medias play important role in the Lewis acid $\mathrm{AlCl}_{3}$ promoted transformations, for instance, the oxidation of alcohol reactions could be carried out in water media, and the well known Ritter reaction taken placed in the solvent of acetonitrile [24]. When we treated alcohol with the readily available $\mathrm{AlCl}_{3}$ in 1, 4-dioxane, surprisingly, different transformation was occurred, chlorinated product was obtained with excellent yields (Scheme 1). In this communication, we wish to report our preliminary investigation on the solvent modulated chlorination of alcohol reactions. The highlights of our system are the following: 1) it offers simple method to activate hydroxyl group by Lewis acid $\mathrm{AlCl}_{3}$, but no electrophilic substitution on the aromatic rings was detected; 2) The regenerated aluminum salt is precipitated from reaction mixture, which could be separated by filtering. The feature is very attractive because it limits the amount of waste typically generated by traditional chlorination reagents and does not lead to environmentally hazardous byproducts.

\section{Results and Discussion}

We then selected 3-methylbenzyl alcohol as a typical substrate to optimize the reaction conditions (Table 1). 


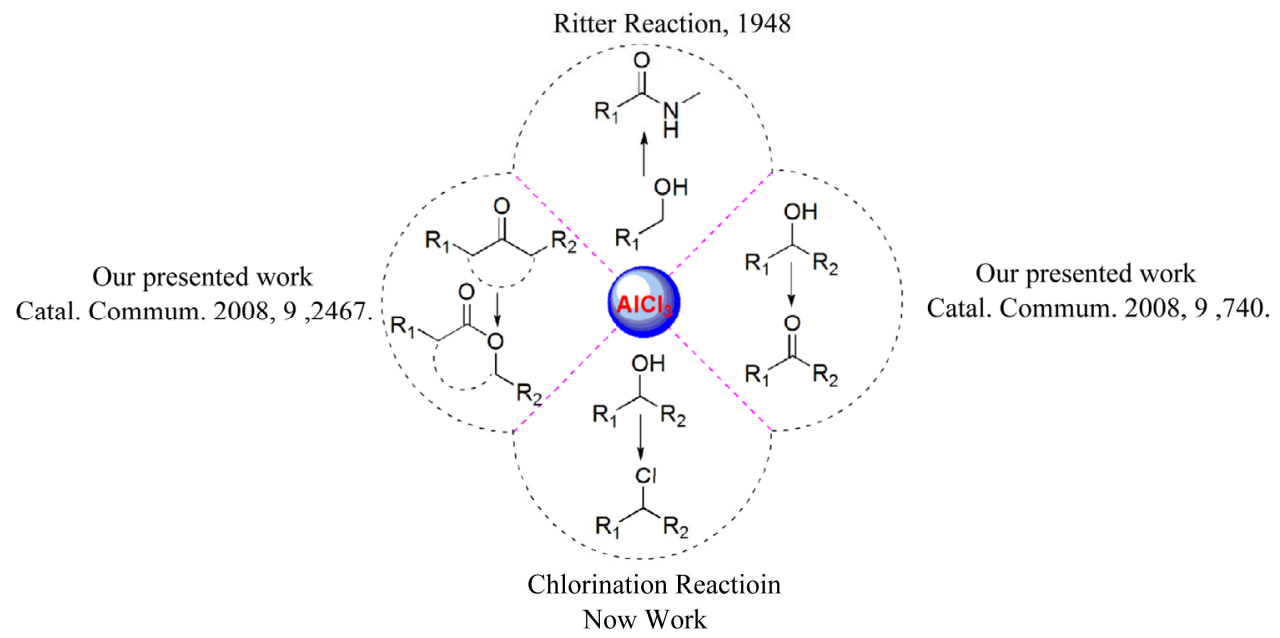

Scheme 1. $\mathrm{AlCl}_{3}$ involved reactions.

Table 1. Study of reaction conditions for the chlorination of 3-methybenzyl alcohol ${ }^{\mathrm{a}}$.

\begin{tabular}{cccccc}
\hline Entry & $\mathrm{AlCl}_{3}(\mathrm{mmol})$ & $\mathrm{T}\left({ }^{\circ} \mathrm{C}\right)$ & Time $(\mathrm{h})$ & Conv. $(\%)^{\mathrm{b}}$ & Sele. $(\%)^{\mathrm{b}}$ \\
\hline 1 & 0.5 & 70 & 5 & 58 & 9 \\
2 & 1.0 & 70 & 5 & 81 & 50 \\
3 & 1.5 & 70 & 5 & 100 & 94 \\
4 & 1.75 & 70 & 5 & 100 & 100 \\
5 & 2.0 & 70 & 5 & 100 & 100 \\
6 & 1.75 & 30 & 5 & 34 & 46 \\
7 & 1.75 & 40 & 50 & 62 & 56 \\
8 & 1.75 & 50 & 5 & 88 & 77 \\
9 & 1.75 & 60 & 5 & 92 & 82 \\
10 & 1.75 & 70 & 5 & 100 & $>99$ \\
11 & 1.75 & 70 & 1 & 76 & 91 \\
12 & 1.75 & 70 & 2 & 87 & 95 \\
13 & 1.75 & 70 & 3 & 99 & 98 \\
14 & 1.75 & 70 & 4 & 99 & 99 \\
\hline
\end{tabular}

${ }^{\mathrm{a}}$ Reaction condition: alcohol $(1.0 \mathrm{mmol}), 1,4$-dioxane $3 \mathrm{~mL} ;{ }^{\mathrm{b}}$ Conversion and selectivity were determined by GC analysis.

Screening of the common used solvents revealed that this conversion occurred in acetone, THF, toluene, $\mathrm{CH}_{2} \mathrm{Cl}_{2}$ and $\mathrm{CHCl}_{3}$, these media were inferior in terms of reaction efficiency. 1, 4-dioxane proved to be the most effective one, furnishing the product in $>99 \%$ conversion, which was probably due to its stronger polarity and better solubility for $\mathrm{AlCl}_{3}$. The quantities of alcohol and $\mathrm{AlCl}_{3}$ were varied to find a suitable ratio to provide the maximum yield of 3-methylbenzyl chloride (entries 1-5). When the amount of alcohol and $\mathrm{AlCl}_{3}$ in a 1:0.5 ratio could produce the corresponding chloride in moderate conversion (entry 1). Increasing the amount of $\mathrm{AlCl}_{3}$ over 1 equiv significantly increased the conversion of the target product (entries 2-5). Elevated temperature ap- parently benefit the reaction, when the reaction mixture was warmed to $70^{\circ} \mathrm{C}, 3$-methylbenzyl alcohol was transformed into product almost quantitative conversion and providing complete bias to aromatic chloride in a short time (entry 13). Meanwhile, we applied other Lewis acids as chlorination reagent, for instance, $\mathrm{ZnCl}_{2}, \mathrm{SnCl}_{2}$, $\mathrm{SnCl}_{4}, \mathrm{FeCl}_{2}, \mathrm{FeCl}_{3}$, etc.; the transformation could not be occurred under the optimized conditions.

Varity of alcohols were investigated to abroad the scope of the reaction (Table 2). Effective transformation was observed in the reaction with the representative aromatic alcohols, all of them could be recovered chemically pure after a simple aqueous workup. For examples, in the cases of 1e, 1f, $\mathbf{1 g}$, methyl and phenoxyl groups exhibited accelerating effect to the chlorination reaction, almost completed conversions and $>96 \%$ selectivity could be obtained. Electron-withdrawing group also demonstrated no negative effect for the transformation, and nitro moieties tolerated these reaction conditions to furnish the corresponding chlorides 2c and 2d in 100\% conversion (entries 3 and 4). Compared to benzylic alcohols, benzhydrol and their derivatives' displayed relatively low activities (entries 8-10). It was also noted that as steric hindrance of the alcohol increased and chlorination reaction could be suppressed, for instance, triphenylmethanol gave the corresponding product in low yield. Under the optimal conditions, attempts to convert aliphatic alcohols into aliphatic halides were disappointed. To address this issue, we increased the amount of $\mathrm{AlCl}_{3}$, and raised the temperature as well as prolonged the reaction time to improve the reaction rate. Under these modified conditions, the chlorination of 1-octanol and cyclohexanol can not be completed; more complicated mixture was produced, and can not be well isolated.

So as to apply the system to industrial research, several representative alcohols were tested in more large scale (Scheme 2). The typical experimental process as 
Table 2. Conversion of aromatic alcohols into the corresponding alkyl halides ${ }^{\mathrm{a}}$.

\begin{tabular}{|c|c|c|c|c|c|}
\hline Entry & Substrate & Product & Conv. $(\%)^{b}$ & Sele. $(\%)^{b}$ & Yield $(\%)^{\circ}$ \\
\hline 1 & & & 99 & 99 & 80 \\
\hline 2 & & & 100 & 100 & 82 \\
\hline 3 & & & 100 & 80 & \\
\hline 4 & & & 100 & 99 & \\
\hline 5 & & & 97 & 96 & 75 \\
\hline 6 & & & 100 & 96 & 78 \\
\hline 7 & & & 100 & 100 & 84 \\
\hline 8 & & & 90 & 80 & 63 \\
\hline 9 & & & 99 & 90 & 72 \\
\hline 10 & & & 90 & 80 & \\
\hline
\end{tabular}

${ }^{\mathrm{a}}$ Reaction condition: alcohol $(1.0 \mathrm{mmol}), 1$, 4-dioxane $3 \mathrm{~mL}, \mathrm{AlCl}_{3}(1.75 \mathrm{mmol}), 3$ hours, $70^{\circ} \mathrm{C}$; ${ }^{\mathrm{b}}$ Conversion and selectivity were determined by $\mathrm{GC}$ analysis. ${ }^{\mathrm{C}} \mathrm{All}$ yields are for pure, isolated products.

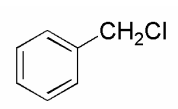

2a, yield $89 \%$<smiles>ClC(c1ccccc1)c1ccccc1</smiles>

2h, $54 \%$

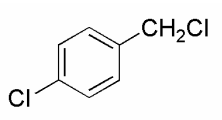

2b, yield $65 \%$<smiles>O=[N+]([O-])c1ccc(CCl)cc1</smiles>

2c, yield $75 \%$

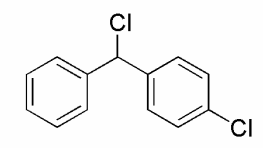

$2 \mathbf{i}, 60 \%$

Scheme 2. Larger scale application.

follows: $\mathrm{AlCl}_{3}$ were added to a solution of alcohol (20 grams) in 1, 4-dioxane. After stirring at $70^{\circ} \mathrm{C}$ for $8-10 \mathrm{~h}$, the crude products were obtained by distillation or recrytallization with good yields ( $>54 \%)$, especially, most crude product's purity was up to $99 \%$.

Basing on the literature [5,25-27], we have proposed a plausible mechanism for the chlorination of alcohol as depicted in Scheme 3. The strong Lewis acid $\mathrm{AlCl}_{3}$ was encapsulated by $\mathrm{OH}$ bond of $\mathrm{ROH}$ leads to the intermediate $\mathbf{I}$ which, when $\mathrm{R}$ is an aryl groups, decomposes either concertedly or via the formation of a carbocation
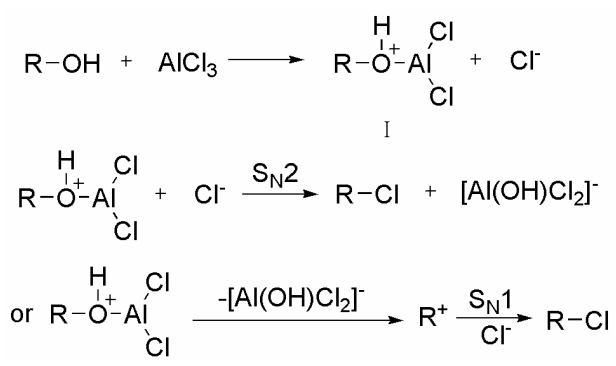

Scheme 3. The plausible reaction mechanism.

into the corresponding alkyl chloride $\mathrm{RCl}$ with the evolution of $\left[\mathrm{Al}(\mathrm{OH}) \mathrm{Cl}_{2}\right]^{-}$.

\section{Experimental}

\subsection{General Information}

$\mathrm{AlCl}_{3}$ are obtained from commercial sources. All of the alcohols used in the reaction were obtained from ABCR $\mathrm{GmbH} \& \mathrm{Co}$. KG. and used as received without further treatment. All NMR spectra are recorded on MERCURY (400 MHz for ${ }^{1} \mathrm{H}$ NMR, $100 \mathrm{MHz}$ for ${ }^{13} \mathrm{C}$ NMR) spec- 
trometers; chemical shifts are expressed in ppm ( $\delta$ units) relative to TMS signal as internal reference in $\mathrm{CDCl}_{3}$. Gas chromatography (GC) analysis was performed on a Shimadezu GC-2010 equipped with a $15 \mathrm{~m} \times 0.53 \mathrm{~mm} \times$ $1.5 \mu \mathrm{m}$ RTX-1 capillary column and a oxyhydrogen flame detector. GC/MS analysis were carried out on a trace HP GC6890/MS5973 equipped with a $25 \mathrm{~m} \times 0.25 \mathrm{~mm}$ SE-54 column and a Shimadzu GC-16A gas chromatograph with a $3 \mathrm{~m} \times 3 \mathrm{~mm} \mathrm{OV}-17$ column.

\subsection{General Procedure for Chlorination Alcohols with $\mathrm{AlCl}_{3}$}

To a $10 \mathrm{~mL}$ round flask were added $1.0 \mathrm{mmol}$ alcohol, 3 $\mathrm{mL}$ of 1, 4-dioxane, and $1.75 \mathrm{mmol} \mathrm{AlCl}_{3}(0.234 \mathrm{~g})$. Then the flask was immersed in a preheated $70^{\circ} \mathrm{C}$ oil bath for $5 \mathrm{~h}$. The mixture was cooled to room temperature, after filtering, $1 \mathrm{~mL}$ water was added to solution, and the sample was extracted with $\mathrm{CH}_{3} \mathrm{COOC}_{2} \mathrm{H}_{5}(3 \mathrm{~mL}$ $\times 4)$. Then the organic layer was dried over anhydrous $\mathrm{Na}_{2} \mathrm{CO}_{3}$ and concentrated to dryness. Isolated product is obtained by column chromatograph. (Petroleum ether/ ethyl acetate $=1 \sim 10: 1, \mathrm{~V} / \mathrm{V})$. The percentage conversion and reaction selectivity were determined by GC analysis.

\subsection{General Procedure for Large Scale Chlorination Alcohols with $\mathrm{AlCl}_{3}$}

To a $100 \mathrm{~mL}$ round flask were added 20 gram alcohol, 60 $\mathrm{mL}$ of 1,4-dioxane, and 1.75 equiv. of $\mathrm{AlCl}_{3}$. Then the flask was immersed in a preheated $70^{\circ} \mathrm{C}$ oil bath for $5 \mathrm{~h}$. The mixture was cooled to room temperature, after filtering, $10 \mathrm{~mL}$ water was added to solution in order to hydrolyze the excessive $\mathrm{AlCl}_{3}$, and the sample was extracted with $\mathrm{CH}_{3} \mathrm{COOC}_{2} \mathrm{H}_{5}(30 \mathrm{~mL} \times 4)$, Then the organic layer was dried over anhydrous $\mathrm{Na}_{2} \mathrm{CO}_{3}$ and concentrated to dryness. The crude product can be obtained by recrystallization or distillation.

\subsection{The Data for Representative Products}

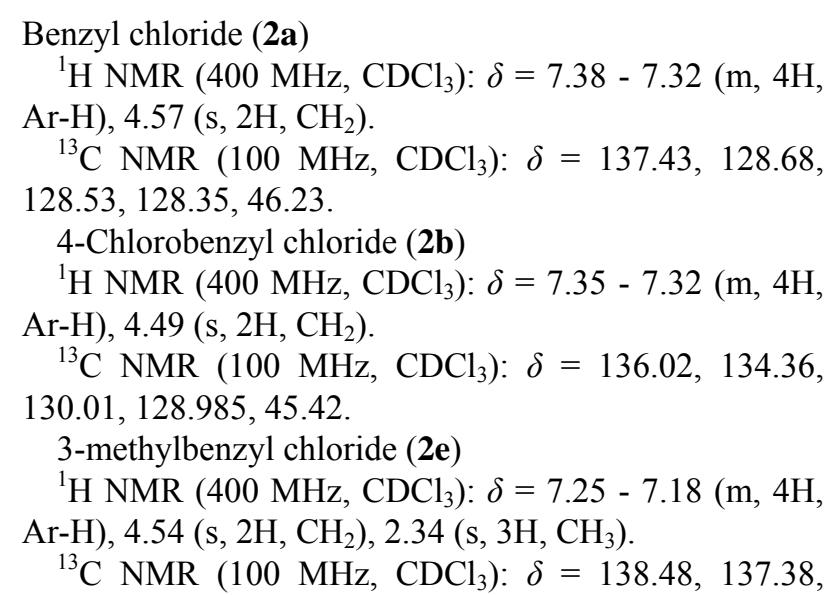

$129.31,129.18,128.64,125.63,46.36,21.32$.

2-methylbenzyl chloride (2f)

${ }^{1} \mathrm{H}$ NMR (400 MHz, $\mathrm{CDCl}_{3}$ ): $\delta=7.34-7.25$ (m, 4H, $\mathrm{Ar}-\mathrm{H}), 4.63\left(\mathrm{~s}, 2 \mathrm{H}, \mathrm{CH}_{2}\right), 2.48\left(\mathrm{~s}, 3 \mathrm{H}, \mathrm{CH}_{3}\right)$.

${ }^{13} \mathrm{C} \mathrm{NMR}\left(100 \mathrm{MHz}, \mathrm{CDCl}_{3}\right): \delta=137.03,135.41$, $130.56,129.64,128.76,126.183,44.65,18.55$.

Chlorodiphenylmethane (2h)

${ }^{1} \mathrm{H}$ NMR (400 MHz, $\left.\mathrm{CDCl}_{3}\right): \delta=7.38-7.31(\mathrm{~m}, 10 \mathrm{H}$, Ar-H), 4.57 (s, H, CH).

$\left.{ }^{13} \mathrm{C} \mathrm{NMR} \mathrm{(100} \mathrm{MHz,} \mathrm{CDCl}_{3}\right): \delta=141.07,128.89$, $128.42,126.03,41.92$.

\section{Conclusion}

In conclusion, we have demonstrated a novel method for chlorination of alcohols using $\mathrm{AlCl}_{3}$ system under mild conditions. The procedure is more convenient with respect to other reports and can be used as a valid alternative to other methods, so avoiding tedious purifications or the use of more toxic reagents. Further utility of this novel system is currently under investigation.

\section{Acknowledgements}

We are grateful for the financial support of the National Natural Science Foundation of China (No.20376071, No. 20674063 and 20774074) and Young Teacher Research Foundation of Northwest Normal University (NWNULKQN-08-8, NWNU-kjcxgc-03-73, NWNU-kjcxgc-0363, 1010RJZA024 ). We also thank Key Laboratory of Eco-Environment-Related Polymer Materials (Northwest Normal University), Ministry of Education, for financial support.

\section{REFERENCES}

[1] T. Hatakeyama, S. Ito, M. Nakamura and E. Nakamura, "Alkylation of Magnesium Enamide with Alkyl Chlorides and Fluorides," Journal of the American Chemical Society, Vol. 127, No. 41, 2005, pp. 14192-14193. doi: $10.1021 / \mathrm{ja} 055306 \mathrm{q}$

[2] D. C. Braddock and J. J.-P. Peyralans, "A General Synthesis of Five, Six and Seven-Membered Silasultones via Dehydrative Cyclisation," Tetrahedron, Vol. 61, No. 30, 2005, pp. 7233-7240. doi:10.1016/j.tet.2005.05.042

[3] M. Yasuda, Y. Onishi, M. Ueba, T. Miyai and A. Baba, "Direct Reduction of Alcohols: Highly Chemoselective Reducing System for Secondary or Tertiary Alcohols Using Chlorodiphenylsilane with a Catalytic Amount of Indium Trichloride," Journal of Organic Chemistry, Vol. 66, 2001, pp. 7741-7744. doi:10.1021/jo0158534

[4] M. Yasuda, T. Saito, M. Ueba and A. Baba, "Direct Substitution of the Hydroxy Group in Alcohols with Silyl Nucleophiles Catalyzed by Indium Trichloride," Angewandte Chemie International Edition, Vol. 43, No. 11, 2004, pp. 1414-1416. doi:10.1002/anie.200353121

[5] M. Yasuda, S. Yamasaki, Y. Onishi and A. Baba, "In- 
dium-Catalyzed Direct Chlorination of Alcohols Using Chlorodimethylsilane-Benzil as a Selective and Mild System," Journal of the American Chemical Society, Vol. 126, No. 23, 2004, pp. 7186-7187. doi:10.1021/ja048688t

[6] G. Bringmann and S. Schneider, "Improved Methods for Dehydration and Hydroxy/Halogen Exchange Using Novel Combinations of Triphenylphosphine and Halogenated Ethanes," Synthesis, Vol. 1983, No. 2, 1983, pp. 139-141. doi:10.1055/s-1983-30255

[7] R. M. Magid, O. S. Fruchey, W. L. Johnson and T. G. Allen, "Hexachloroacetone/Triphenylphosphine: A Mild Reagent for the Regioselective and Stereospecific Production of Allylic Chlorides from the Alcohols," Journal of Organic Chemistry, Vol. 44, No. 3, 1979, pp. 359-363. doi:10.1021/jo01317a011

[8] D. O. Jang, D. J. Park and J. Kim, "A Mild and Efficient Procedure for the Preparation of Acid Chlorides from Carylic Acids," Tetrahedron Letters, Vol. 40, No. 29, 1999, pp. 5323-5326. doi:10.1016/S0040-4039(99)00967-3

[9] R. G. Weiss and E. I. Snyder, "Stereochemistry of Displacement Reactions at the Neopentyl Carbon. Further Observations on the Triphenylphosphine-Polyhalomethane-Alcohol Reaction," Journal of Organic Chemistry, Vol. 36, 1971, pp. 403-406. doi:10.1021/jo00802a009

[10] T. Fujisawa, S. Iida and T. Sato, "A Convenient Method for the Transformation of Alcohols to Alkyl Chlorides Using N,N-Diphenylchlorophenylmethyleniminium Chloride," Chemistry Letters, Vol. 13, 1984, pp. 1173-1174. doi:10.1246/cl.1984.1173

[11] T. Mukaiyama, S. I. Shoda and Y. Watanabe, "A New Synthetic Method for the Transformation of Alcohols to Alkyl Chlorides Using 2-Chlorobenzoxazolium Salt," Chemistry Letters, Vol. 6, 1977, pp. 383-386. doi:10.1246/cl.1977.383

[12] M. Benazza, R. Uzan, D. Beaupère and G. Demailly, "Direct Regioselective Chlorination of Unprotected Hexitols and Pentitols by Vilsmeier and Haack's Salt," Tetrahedron Letters, Vol. 33, No. 34, 1992, pp. 4901-4904. doi:10.1016/S0040-4039(00)61228-5

[13] M. Benazza, R. Uzan, D. Beaupère and G. Demailly, "Direct Regioselective Chlorination of Unprotected Hexitols and Pentitols by Viehe's Salt," Tetrahedron Letters, Vol. 33, 1992, pp. 3129-3132. doi:10.1016/S0040-4039(00)79831-5

[14] R. C. Larock, "Comprehensive Organic Transformations," 2nd Edition, Wiley-VCH, New York, 1999, pp. 689-702.

[15] J. E. Copenhaver and A. M. Whaley, "Organic Syntheses," Wiley and Sons, New York, Vol. 1, 1941, pp. 144145.

[16] E. S. Lewis and C. E Boozer, Journal of the American Chemical Society, Vol. 74, 1952, pp. 308-311.

[17] R. E. Ireland, D. W. Norbeck, G. S. Mandel and N. S.
Mandel, "Convergent Synthesis of Polyether Ionophore Antibiotics: An Approach to the Synthesis of the Monensin Tetrahydropyran-Bis(Tetrahydrofuran) via the Ester Enolate Claisen Rearrangement and Reductive Decarboxylation," Journal of the American Chemical Society, Vol. 107, No. 11, 1985, pp. 3285-3294. doi:10.1021/ja00297a039

[18] J. G. Lee and K. K. Kang, "Selenium Dioxide Catalyzed Conversion of Alcohols to Alkyl Chlorides by Chlorotrimethylsilane," Journal of Organic Chemistry, Vol. 53, No. 15, 1988, pp. 3634-3637. doi:10.1021/jo00250a048

[19] R. M. Magid, O. S. Fuchey and W. J. Johnson, "Hexachloroacetone/Triphenylphosphine: A Reagent for the Regio- and Stereoselective Conversion of Allylic Alcohols into Chlorides," Tetrahedron Letters, Vol. 18, No. 35, 1977, pp. 2999-3002. doi:10.1016/S0040-4039(01)83138-5

[20] T. T. Slage, T. T.-S. Huang and B. Franzus, "Mechanism of the Triphenylphosphine-Tetrachloromethane-Alcohol Reaction: Pericyclic or Clustered Ion Pairs?" Journal of Organic Chemistry, Vol. 46, 1978, pp. 3526-3530. doi:10.1021/jo00330a030

[21] P. J. Garegg, R. Johansson and B. Samuelsson, "Two Reagent Systems for Converting Hydroxy Compounds into Chlorides using the Triphenylphosphine/Imidazole System," Synthesis, Vol. 1984, No. 2, 1984, pp. 168-170. doi:10.1055/s-1984-30769

[22] Z. Q. Lei and R. R. Wang, "Oxidation of Alcohols Using $\mathrm{H}_{2} \mathrm{O}_{2}$ as Oxidant Catalyzed by $\mathrm{AlCl}_{3}$. Baeyer-Villiger Oxidation of Ketones with Hydrogen Peroxide Catalyzed by Silica Supported Aluminum Chloride," Catalysis Communications, Vol. 9, 2008, pp. 740-742. doi:10.1016/j.catcom.2007.08.012

[23] Z. Q. Lei, L. L. Wei, R. R. Wang and G. F. Ma, "Baeyer-Villiger Oxidation of Ketones with Hydrogen Peroxide Catalyzed by Silica Supported Aluminum Chloride," Catalysis Communications, Vol. 9, No. 15, 2008, pp. 2467-2469. doi:10.1016/j.catcom.2008.06.022

[24] J. J. Ritter and P. P. Minieri, "A New Reaction of Nitriles. I. Amides from Alkenes and Mononitriles," Journal of the American Chemical Society, Vol. 70, 1948, pp. 40454048. doi:10.1021/ja01192a022

[25] W. Pluempanupat and W. Chavasiri, "An Efficient Method for Chlorination of Alcohols Using $\mathrm{PPh}_{3} /$ $\mathrm{Cl}_{3} \mathrm{CCONH}_{2}$," Tetrahedron Letters, Vol. 37, No. 51, 2006, pp. 6821-6823. doi:10.1016/j.tetlet.2006.07.060

[26] L. D. Luca, G. Giacomelli and A. Porcheddu, "An Efficient Route to Alkyl Chlorides from Alcohols Using the Complex TCT/DMF," Organic Letters, Vol. 4, No. 4, 2002, pp. 553-555. doi:10.1021/o1017168p

[27] A. Dubey, A. K. Upadhyay and P. Kumar, "Pivaloyl Chloride/DMF: A New Reagent for Conversion of Alcohols to Chlorides," Tetrahedron Letters, Vol. 51, No. 4, 2010, pp. 744-746. doi:10.1016/j.tetlet.2009.11.131 